\section{Review Article}

J Exp Clin Med

2021; 38(S2): 113-118

doi: $10.52142 /$ omujecm.38.si.dent.6

\title{
Digital imaging and dental record
}

\author{
Gözde SERINNDERE ${ }^{1, *}$, Kaan GÜNDÜZ ${ }^{2}$ [D \\ ${ }^{1}$ Department of Dentomaxillofacial Radiology, Faculty of Dentistry, Hatay Mustafa Kemal University, Hatay, Turkey \\ ${ }^{2}$ Department of Dentomaxillofacial Radiology, Faculty of Dentistry, Ondokuz Mayis University, Samsun, Turkey
}

\begin{abstract}
\begin{tabular}{ccccc}
\hline Received: 15.05 .2020 & $\bullet$ & Accepted/Published Online: 17.12 .2021 & $\bullet$ & Final Version: 19.05 .2021 \\
\hline
\end{tabular}
\section{Abstract}

One of the most important developments in the field of radiology is that the imaging process has started to take place in the digital environment. The advantages of digital radiography increase the interest of dentists in digital radiography, and nowadays digital systems are replacing conventional systems. The most important reasons for the increase of using the digital systems are the fast access to the image, the quality of the image, and the easy storage and transmission of the image. Nowadays, clinicians can digitize anything and recall it with the patient. This article presents a review of digital imaging and dental record. The history of digital imaging, direct and indirect digital imaging methods, digital sensors, and dental records were reviewed.
\end{abstract}

Keywords: dental records, digital imaging, image analysis, image processing

\section{Introduction}

\subsection{The history of digital radiology}

Digital radiography (DR) is considered one of the most important developments in the field of dentistry in recent years. DR systems consist of a conventional X-ray machine, a receiver (sensor or screen) instead of a film, and a computer with suitable software. A high-resolution monitor complements the system (Wenzel and Gröndahl, 1995). The first digital X-ray sensor used in dentistry was invented by Francis Mouyen in the mid-1980s (RVG, Trophy Radiologie, Croissy Beaubourg, France). The event that inspired the invention of dental intraoral sensors has been a challenge for Mouyen during his student years as he moved between departments for radiographic procedures during endodontic treatment (Farman, 2003; Farman, 2006).

\subsection{Digital imaging system}

Digital imaging includes X-ray interaction with electrons in sensor pixels, converting analog data to digital data, computer phase, and showing of the apparent image on a computer monitor. Data obtained by the sensor is transmitted to the computer in analog form. The computer operates on the binary number system that two digits ( 0 and 1$)$ are benefited from represent data. These digits are determined as bits and they create words eight or more bits termed as bytes. The total number of bytes for 8-bit is calculated as $256\left(2^{8}\right)$. The analogto-digital converter becomes analog data to numerical data depending on the system of the binary number. The signal

voltage is calculated and transferred a number from 0 indicating black to 255 indicating white based on the voltage intensity. The numerical assignation translates into 256 shades of gray. The eye of the human can determine about 32 gray levels (Bushong, 2001). Some digital systems sample the raw data with a resolution that is more than 256 gray values as 10 bit or 12 bit (van der Stelt, 2000).

When conventional radiographs are examined on a negatoscope, the structure of the different densities of silver grains is perceived by the eye as different layers of gray. In the digital system, many photosensitive small elements are used instead of silver halide crystals for image recording. Different gray layers are produced in the light emitted from the computer screen to reflect the image. In the analog image, while the silver grains are randomly distributed in the emulsion, the digital image contains a large collection of pixels (image elements) in an organized matrix of rows and columns. Since these picture elements are small, they cannot be seen with normal magnification (van der Stelt, 2000; Ludlow and Mol, 2004). There are some features required in a digital imaging system (Farman and Farman, 2005):

- The diagnostic quality of the generated image should be good

- The radiation dose used should be equal to or lower than 
the film

- Digital radiography techniques should be compatible with conventional X-ray devices

- It allows information flow within Digital Imaging and Communication in Medicine (DICOM) standards

- The time required for all operations must be less than or equal to the film

\subsection{Digital sensors}

Digital images can be obtained either directly or semi-directly using a detector or indirectly by scanning and converting an existing conventional radiograph into a digital image (Kamburoğlu and Paksoy, 2010).

\subsubsection{Indirect method}

In the indirect method, a film-based radiograph is needed. A device is used to scan or take a photograph of a film-based radiograph. A camera or scanner can be used for the indirect method. By using digital cameras, a digital image can be created directly. One disadvantage is that the camera may be handheld, and the camera shakes and poor-quality images may occur. This disadvantage can be avoided by using a tripod camera (Langland et al., 2002).

Scanners provide a fast and easy way of converting radiographs to images. The scanner passes a light beam through the radiograph to a chip termed as a charge-coupled device (CCD) CCD that converts the light to a digital image (Langland et al., 2002).

\subsubsection{Directed method}

In the direct method, films are not required. The digital image is obtained by the sensor (Langland et al., 2002). Direct digital systems are real-time solid-state detectors. Generally, direct digital systems use a CCD and complementary metal-oxidesemiconductor / active pixel sensor (CMOS/APS) technology. Semi-direct detectors are phosphor plates (photostimulable phosphor storage plate) (Whaites, 2002; Langlais, 2004).

\section{Charged coupled device (CCD)}

CCD sensor includes a sensor that is placed in the patient's mouth. A cable leads from the sensor to an interface, which is connected to a computer in the operatory. The CCD also includes a pixel array on a silicon chip (Dhir et al., 2014).

$\mathrm{CCD}$ is an integrated circuit that consists of a grid of small transistor components converting X-ray to an electron. When $\mathrm{X}$-ray photons reach to transistor component, electrons are trapped in the wells according to the number of striking X-rays. The transistor is arranged in a grid formation. Each component describes as a pixel of the final image. After exposure, the components are read, stored electron charge is converted into brightness value and a digital image is formed (Langland et al., 2002).

The scintillation screen and fiber-optic plate made CCD thicker. Patient comfort reduced due to the thick sensor.
However, the size of modern CDD sensors is similar to No.2 periapical film and has a thickness as lower as 3 to $5 \mathrm{~mm}$ (Langland et al., 2002).

\section{Complementary metal-oxide-semiconductor (CMOS)}

CMOS sensor is an option to CCD sensor and does not require charge transfer that increases sensor reliability and lifespan. Additionally, less system power to operate and lower cost is needed (Parks and Williamson, 2002).

\section{Photostimulable phosphor plates (PSP)}

Phosphor plates contain a barium fluor halide phosphorus layer. Repeatedly used plate, photon generated by X-ray absorption and stores its energy. The image plate is then scanned by a laser beam in a reader. The energy in the phosphorus layer is released in the form of light detected by a photomultiplier. Thus, the information is transferred to the computer and observed on the monitor (Akdeniz, 2000; Whaites, 2002; Langlais, 2004). To obtain the best quality images, it is ideal to scan phosphor plates in the first ten minutes. Plates should be stored in a light-tight environment if longer periods are to be expected and no scanning is possible within the first ten minutes (Akdeniz et al., 2005).

At least $50 \%$ of the radiation dose is required by using PSP than a film. Using a lack of film processing repeatedly and wide exposure range are important advantages. Another advantage of the phosphor plate is that it has film dimensions and is not connected to the computer by a cable (Langland et al., 2002). The PSP is placed in a plastic pouch to prevent oral saliva contamination and to control infection (Dhir et al., 2014).

\subsection{Extraoral digital imaging}

Extraoral digital imaging can be accomplished utilizing direct or indirect digital imaging systems. There are several panoramic systems available that use either linear array CCD or PSP plate sensors. The cost of the sensor, the time needed to capture the image data, and file size are all considerations that must be evaluated when considering a digital panoramic system. In either case, the method is like conventional panoramic radiography, but the receptor, processing, display, and storage differ from film-based imaging (Farman and Farman, 2000).

The PSP for extraoral imaging is a similar size to conventional film. There is an excessive costto produce an area array the size of a panoramic film using either CCD or CMOS. As a result, the trade-off is describing the smallest size of an array that can capture an extraoral image. The panoramic radiography design of the CCD or CMOS area array is less complex because of capturing only a small part of the image (Parks and Williamson, 2002).

\subsection{The factors affecting digital image quality}

The higher the visibility of anatomical and pathological structures on an image, the higher the quality of that image (Çağlayan and Harorlı, 2020). 


\subsubsection{Resolution}

A quality image is provided by clearly showing the smallest structure that the system can view. Resolution is the capacity to distinguish two objects close to each other. The concepts of "contrast resolution" and "spatial resolution" are mentioned in digital images (Udupa et al., 2013; Harorlı, 2014; HellénHalme et al., 2016; Toraman Alkurt and Demirel, 2016).

\subsubsection{Contrast resolution}

Changes in anatomical or pathological structures create images of different tones and intensities due to different absorption of $\mathrm{x}$-ray. The ability to distinguish different densities in the image is called "contrast resolution." (Udupa et al., 2013; HellénHalme et al., 2016). The contrast resolution of digital systems is higher than conventional radiography (Harorl1, 2014; Toraman Alkurt and Demirel, 2016).

\subsubsection{Spatial resolution}

Spatial resolution is the capacity to distinguish details in an image. It can also be defined as the ability to show two different structures standing side by side. The higher the number of distinguishable structures per unit area in an image, the higher the dimensional resolution of that image. When calculating the resolution, special test materials that consist of gaps of the same width as the radiopaque lines are used. In this test, a line and a space adjacent to it are called a "line pair" (Seely et al., 2008; Harorl1, 2014; ToramanAlkurt and Demirel, 2016). At least two pixels are required to analyze the line pair, one dark line, and one light line. Resolution is measured in units of line pair per millimeter (line pair / mm "lp / mm") (Çağlayan and Harorl1, 2020).

The thinner line pair a viewing system can separate, the higher the spatial resolution of that system. The resolution of periapical films (including E-group) is about $20 \mathrm{lp} / \mathrm{mm}$ (Misirlı and Orhan, 2016). The resolution of the sensors varies between $7-27 \mathrm{lp} / \mathrm{mm}$. The spatial resolution of phosphor plate systems values ranges from 10-21 lp/mm (Harorl1, 2014; Toraman Alkurt and Demirel, 2016).

\subsubsection{Noise}

These are changes caused by the imaging system that impair the image quality but cannot be completely prevented. Noise degrades the quality of the image, gives it a mottled appearance, and prevents low contrast objects from being seen. Since scintillation crystals equivalent to ranforsator are used in some digital systems, structural speckling that may occur in them is among the noise sources. Noise sources are divided into electronic noise and digitalization noise (Harorl1, 2014; Kaya, 2014; Özcan and Yurdabakan, 2017).

Electronic noise is the distortion created by all electronic components in the image (Harorl1, 2014; Kaya, 2014).

Digitization noise is the grayscale coding difference caused by the display of an image obtained with high bit depth in a low bit depth environment. For example, if an image obtained with 10 bits (1024 shades of gray) is displayed on a monitor with 8 bits (256 shades of gray), one of every four grayscale levels obtained will be distributed into grayscale in the display environment, and as a result, the image will be distorted. For this reason, systems should be designed at bit depths that are as high as possible, yet still compatible (Harorl1, 2014; Kaya, 2014).

\subsubsection{Dynamic range}

In digital radiology, the dynamic range determines the system's capacity to convert changing photon energies into images. Systems that can transform the information carried by photons with minimum and maximum energy into images are systems with a wide dynamic range (Harorl1, 2014; Toraman Alkurt and Demirel, 2016).

\subsection{Image processing}

Operations to improve, correct, analyze, or modify an image are known as image processing. The aim is to create more selectable images for the human eye or to obtain data by analyzing the image content (Mol, 2000). It is possible to obtain more pleasing images with subjective reinforcement. Nowadays many of the software packages offer image processing techniques. The selection of the appropriate one of these techniques is determined by the imaging model, diagnostic objective, and observation conditions (Analoui, 2001).

Diagnostic areas that clinicians expect to benefit from using image processing in digital systems are mostly the diagnosis of caries, periodontal and periapical lesions, and bone lesions. With the automation of the processing, a faster and more accurate diagnosis will be possible (Li et al., 2006).

When an image is captured, it is digitized, various computerized enhancements may be performed on the image. Density and contrast can both be changed. Density can be changed by adding or subtracting the same value to each pixel. Contrast can also be changed by a difference in the gradient of the gray level on the image. Other image enhancements are the inversion of the grayscale that can be explained by the displacement between black and white, magnification, and pseudocolor enhancement (Parks and Williamson, 2002).

Filters that smooth the image, eliminate high-frequency noise. Image sharpening filters eliminate low-frequency noise or sharpen by strengthening the boundaries between different intense zones (edge reinforcement) (Ludlow and Mol, 2004).

\subsection{Image analysis}

Image analysis operations are designed to extract diagnostically relevant information from the image which can range from simple linear measurements to fully automated diagnosis. An example of image analysis is the measurement of a distance in a digital image (Dhir et al., 2014).

Using automatic measuring tools, length, angle, and area calculations can be made on the digital image. The easiest way to do this is to specify measurements as pixel numbers. Another method is to use millimeters or inches as units of 
measurement. To convert pixel measurements to actual length measurements, it is necessary to calibrate the magnification factor of the sensor used (van der Stelt, 2005).

\subsection{Advantages and disadvantages of digital imaging}

There are some advantages such as $50-70 \%$ less radiation dose, decreased time between exposure and image acquisition, manipulation ability, clear diagnostic image, lack of radiograph chemical processing, and ease of electronically storing patient records (Lačević and Vranić, 2004). Disadvantages can be stated as size, shape, thickness, and rigidity of the sensor, lower image resolution, high cost, unknown use time of the sensor, difficulties for infection control (Miles,1993; Farman et al., 1995). The sterilization of CCD sensors cannot be done. Saliva contamination to the sensor and electrical cable should prevent cross-contamination (Parks and Williamson, 2002). During CCD use, mistakes and retakes of images may occur because of patient discomfort (Versteeg et al., 1998). Versteeg et al. (1998) reported horizontal placement errors, particularly in molar regions, and vertical angulation errors, in the anterior regions where the incisal area was cut off and not visible. $28 \%$ of CCD images were found as unacceptable and retakes were required compared to $6 \%$ for films.

\section{Dental record}

A dental record is a detailed document including the disease history, clinical examination, diagnosis, and treatment planning of a patient. Dentists are obliged by law to have sufficient dental records. With increased public awareness of the legal issues surrounding health care and increased concern for cases of malpractice, comprehensive knowledge of dental registration issues is required for any practitioner. The ability of clinical practitioners to produce and maintain accurate dental records is a legal obligation as well as quality patient care. A dental record provides continuity of care to the patient and is critical in the event of a claim for malpractice insurance (Lawney, 1998).

Comprehensive and accurate records are a vital part of the practice of dentistry. Good record-keeping is essential for good clinical practice and an indispensable skill for practitioners. The main purpose of keeping dental records is to provide quality patient care and follow-up. Dental records can also be used for forensic purposes (Charangowda, 2010). Teeth are less affected by physical and external factors than other organs and can maintain their shape and structure for a long time. Many studies have been conducted on the identification of teeth since they can often be found with the corpse, they survive more than other body tissues after death and show differences even in identical twins (Fischman, 1985; Agnihotri et al., 2008; Jayawardena et al., 2009).

According to the Australia Guidelines on Dental Records (2010);

- General principles;
- A dental record should be made during or after an appointment as soon as possible

- Entries on a dental record should be made in chronological order

- Entries on a dental record should be accurate and concise

- The dental records should be easily understandable by third parties (in particular another dentist). Access by third parties is subject to the application of the provisions of confidentiality legislation

- Dental records should be retrievable promptly when required

- Dental records should be stored securely and protected against loss or damage including the safe backup of electronic records

- Dentists should be aware of the local privacy laws governing the maintenance of records that must be kept for 7-10 years

- All comments should be in objective and nonemotional language

- Dentists should be aware of the requirements of the Board's Code of Conduct in 3.16 regarding the closure of an application. The rules require the transfer or proper management of all patient records according to the legislation governing health records in the jurisdiction

- Corrections to records should not remove the original information

- A dentist who conducts the treatment should not delegate responsibility for the accuracy of medical and dental information to another person.

- Determine patient details

- Information for the record;

1) Patient details

- Determine patient details

- Completed and current medical history, including adverse drug reactions

\section{2) Clinical information}

a) Accurate documentation;

- Visit date

- Descriptive details of the practitioner providing the treatment

- Information about the type of examination

- The patient complaint

- Patient history

- Clinical findings and observations 
- Diagnosis

- Treatment planning and options

- $\quad$ Patient consent, client, or consumer

- All procedures carried out

- Instrument batch (tracking) control identification, where relevant

- A prescribed, administered, or given drug/drug or any other therapeutic agent used (name, amount, dose, instructions)

- Details of advice provided.

b) Unusual treatment sequelae

c) Radiographs and other relevant diagnostic data; digital radiographs should be easily transferable and available in highresolution digital media

d) Other digital information such as CAD-CAM restoration files

e) Instructions to laboratories and communication with laboratories

\section{3) Other information}

- All referrals to other practitioners and other practitioners

- Any communication with or relating to the patient, customer, or consumer

- Details of dental record contributors

- Fee estimations or quotations (Australia Guidelines on Dental Records, 2010).

Most clinicians believe that record keeping is sufficient. There is an inconsistency between the dentist's perception of the adequacy of dental registration and the proposed structure and guidelines. When pieces of evidence from studies in the United States, Australia, Scandinavia, and the United Kingdom are examined, it is true. It has been found that the basic clinical entries that may affect the delivery of basic dental care are lacking in many records. The frequency of enrollment for patients whose treatment is financed under government regulations is much worse than for patients whose treatment is privately funded (Osborn et al., 2000; Morgan, 2001). In the study of Osborn et al. (2000), it was reported that Minnesota dentists' perception of the sufficiency of their dental records, $85 \%$ of dentists expected their records were sufficient but, 9$87 \%$ of the time information was observed to be absent when compared with the American Dental Association (ADA) criteria. Astekar et al. (2011) reported that only 38\% of the dentists in Rajasthan were aware of the importance of keeping dental records. Preethi et al. (2011) found that it was found that $21 \%$ did not keep any dental records and that only $12 \%$ maintained full dental records among dental clinicians in Chennai.

In the article reported by the College of Dental Surgeons of British Columbia (1996), dental records should be protected from unauthorized use or disclosure, even to family members, except where required by law or where the patient expressly consents to them in writing. All dental records must be safely stored and never left unattended. If an electronic system is used to enter patient records, a login name and password must be available to access the data. All original records of the patient are the exclusive property and responsibility of the treating dentist and must be in custody. If the patient is moved to a different dental office, a copy of the records should be transferred to the new practitioner.

Patients do not have the right to have original records. However, they have the right to access complete dental records and to have a copy, and the dentist is obliged to submit these copies, even in case of disagreements or fees (Devadiga, 2014).

According to the Records Management Code of Practice for Health and Social Care (2016), the retention period of general dental services records is 10 years. It has been reported to be reviewed and destroyed if no longer required.

\section{Conclusions}

Digital imaging is a powerful method for dentists with the features of being reliable and versatile. So, this technology expands the diagnostic and image-sharing opportunities of dental radiology (Dhir et al., 2014).

Nowadays, keeping patient records in dentistry does not meet the guidelines in many ways. If patient records need to be improved by adopting the transition to electronic recordkeeping, the profession should seek to expand traditional record-keeping formats to overcome the practical problems of keeping dental records accurate and contemporary. Adopting the use of digital voice recording can provide an easily accessible and easy to use solution (Brown, 2015).

\section{References}

1. Agnihotri, G., Gulati, M.S., 2008. Maxillary molar and premolar indices in North Indians: A dimorphic study. Internet J. Biol. Anthropol. 2(1).

2. Akdeniz, B.G., Gröndahl, H.G., Kose, T., 2005. Effect of delayed scanning of storage phosphor plates. Oral. Surg. Oral. Med. Oral.Pathol. Oral. Radiol. Endod. 99(5), 603-607.

3. Akdeniz, G., 2000. Modern Imaging Modalities (II). Ankara. Üniv. Diş. Hek. Fak. Derg. 27(2), 271-276.

4. Analoui, M., 2001. Radiographic image enhancement. Part I: Spatial domain techniques. Dentomaxillofac. Radiol. 30, 1-9.

5. Astekar, M., Saawarn, S., Ramesh, G., Saawarn, N., 2011. Maintaining dental records: Are we ready for forensic needs? J. Forensic. Dent. Sci. 3, 52-57.

6. Brown, L.F., 2015. Inadequate record-keeping by dental practitioners. Aust. Dent. J. 60, 497-502.

7. Bushong, S.C., 2001. Radiologic science for technologists: Physics, biology, and protection. $7^{\text {th }}$ Edition. St. Louis, CV Mosby, pp. 374.

8. Charangowda, B.K., 2010. Dental records: An overview. J. Forensic. Dent. Sci. 2, 5-10.

9. Çağlayan, F., Harorlı, A., 2020. Diş Hekimliğinde Dijital 
Görüntüleme Sistemleri [Digital Imaging Systems in Dentistry]. Atatürk. Üniv. Diş. Hek. Fak. Derg. 30 (1), 138-147.

10. Dental records management. College of Dental Surgeons of British Columbia, 1996.

from: http://www.cdsbc.org/ ASSETS/DOCUMENT/Dental-

Records-Mgt.pdf.

11. Devadiga, A., 2014. What's the deal with dental records for practicing dentists? Importance in general and forensic dentistry.J. Forensic. Dent. Sci. 6, 9-15.

12. Dhir, P., David, C.M., Keerthi, G., Sharma, V., Girdhar, V., 2014. Digital imaging in Dentistry: An overview. Int. J. Med. Dent. Sci. 3, 524-532.

13. Farman, A.G., Scarfe, W.C., Schick, D.B., Rumack, P.M., 1995. Computed dental radiography: Evaluation of a new chargecoupled- devices-based intraoral radiographic system. Quintessence Int. 26, 399-404.

14. Farman, A.G., Farman, T.T., 2005. A comparison of 18 different X-ray detectors currently used in dentistry. Oral. Surg. Oral. Med. Oral. Pathol. Oral. Radiol. Endod. 99(4), 485-489.

15. Farman, A.G., Farman, T.T., 2000. Extraoral and Panoramic Systems. Dent. Clin. North. Am. 44, 257-272.

16. Farman, A.G., 2003. Fundamentals of image acquisition and processing in the digital era. Orthod. Craniofac. Res. 6, 17-22.

17. Farman, A.G., 2006. Image-guidance the revolution in dental treatment facilitated by digital radiology. Oral. Surg. Oral. Med. Oral. Pathol. Oral. Radiol. Endod.101, 273-275.

18. Fischman, S.L., 1985. The use of medical and dental radiographs in identification. Int. Dent. J. 35, 301-306.

19. Guidelines on dental records. Dental Board of Australia. 2010.

20. Harorlı, A., 2014. Ağız Diş ve Çene Radyolojisi. 2. Bask1. Erzurum: Nobel Tip Kitabevleri, pp. 191-205.

21. Hellén-Halme, K., Johansson, C., Nilsson, M., 2016. Comparison of the performance of intraoral X-ray sensors using objective image quality assessment. Oral. Surg. Oral. Med. Oral. Pathol. Oral. Radiol. 121, e129-37.

22. Jayawardena, C.K., Abesundara, A.P., Nanayakkara, D.C., Chandrasekara, M.S., 2009. Agerelated changes in crown and root lenght in Sri Lankan Sinhalese. J. Oral. Sci. 51, 587-592.

23. Kamburoğlu, K., Paksoy, C.S., 2010. Diş Hekimliğinde Dijital Radyografi. Turkiye. Klinikleri. J Dental Sci. 16, 164-173.

24. Kaya, T., 2014. Radyografik Kalite. Radyografi. 3, 55-59.

25. Lačević, A.,Vranić, E., 2004. Different digital imaging techniques in dental practice. Bosn. J. Basic. Med. Sci. 4, 37-40.

26. Langlais, R.P., 2004. Exercises in Oral Radiology and Interpretation. $4^{\text {th }}$ ed. St Louis: Saunders, pp. 67-71.

27. Langland, O.E., Langlais, R.P., Preece, J.W., 2002. Principles of dental imaging. $\quad 2^{\text {nd }}$ ed. Philadelphia: Lippincott Williams\&Wilkins, pp. 283-285.

28. Lawney, M., 1998. For the Record. Understanding Patient Recordkeeping. N Y. State. Dent. J.64, 34-43.

29. Li, G., van der Stelt, P.F., Verheij, J.G., Speller, R., Galbiati, A., Psomadellis, F., et al., 2006. End-user survey for digital sensor characteristics: A pilot questionnaire study. Dentomaxillofac. Radiol. 35,147-151.
30. Ludlow, J.B., Mol, A., 2004. Digital imaging. In: White SC, Pharoah MJ, eds. Oral Radiology Principles and Interpretation. $5^{\text {th }}$ ed. St. Louis: Mosby, pp. 225-244.

31. Misırl1, M., Orhan, K., 2016. Dijital Panoramik ve Temporomandibular Eklem Grafileri [Digital Panoramic and Temporomandibular Joint Graphies]. Turkiye. Klinikleri. J. Oral. Maxillofac. Radiol-Special. Topics. 2, 42-50.

32. Miles, D., 1993. Imaging using solid-state detectors. Dent. Clin. N. Am.37, 531-540.

33. Mol, A., 2000. Image processing tools for dental applications. Dent. Clin. North. Am. 44, 299-318.

34. Morgan, R.G., 2001. Quality evaluation of clinical records of a group of general dental practitioners entering a quality assurance programme. Br. Dent. J. 191, 436-441.

35. Osborn, J.B., Stoltenberg, J.L., Newell, K.J., Osborn, S.C., 2000. Adequacy of dental records in clinical practice: A survey of dentists. J. Dent. Hyg. 744, 297-306.

36. Özcan, İ., Yurdabakan, Z.Z., 2017. "Dijital Radyoloji”, Diş Hekimliğinde Radyolojinin Esasları. İstanbul: Medikal Yayıncılık, pp. 205-225.

37. Parks, E.T., Williamson, G.F., 2002. Digital Radiography: An Overview. J. Contemp. Dent. Pract. 3, 1-13.

38. Preethi, S., Einstein, A., Sivapathasundharam, B., 2011. Awareness of forensic odontology among dental practitioners in Chennai: A knowledge, attitude, practice study. J. Forensic. Dent. Sci. 3, 6366.

39. Information Governance Alliance, 2016. Records management code of practice for health and social care 2016. https://digital.nhs.uk/data-and-information/looking-afterinformation/data-security-and-information-governance/codes-ofpractice-for-handling-information-in-health-and-care

40. Seely, J.F., Holland, G.E., Hudson, L.T., Henins, A., 2008. X-ray modulation transfer functions of photostimulable phosphor image plates and scanners. Appl. Opt. 47, 5753-5761.

41. Toraman Alkurt, M., Demirel, O., 2016. Dijital Sensörlerin Özellikleri [Digital Detector Characteristics].Turkiye Klinikleri. J. Oral. Maxillofac. Radiol-Special. Topics. 2, 10-13.

42. Udupa, H., Mah, P., Dove, S.B., McDavid, W.D., 2013. Evaluation of image quality parameters of representative intraoral digital radiographic systems. Oral. Surg. Oral. Med. Oral. Pathol. Oral. Radiol. 116, 774-783.

43. van der Stelt, P.F., 2005. Filmless imaging: The uses of digital radiography in dental practice. J. Am. Dent. Assoc. 136 (10), 13791387.

44. van der Stelt, PF., 2000. Principles of digital imaging. Dent. Clin. North. Am. 44, 237-248.

45. Versteeg, C.H., Sanderick, G.C., van Ginkel, F.C., et al., 1998. An evaluation of periapical radiography with a charge couple devices. Dentomaxillofac. Radiol. 27, 97-101.

46. Wenzel, A., Gröndahl, H.G., 1995. Direct digital radiography in the dental office. Int. Dent. J.45, 27-34.

47. Whaites, E., 2002. Alternative and specialized imaging modalities. Essentials of Dental Radiography and Radiology. $3^{\text {rd }}$ ed. Edinburgh: Churchill, pp. 191-208 